\title{
Energy Investigation Framework: Understanding buildings from an energy perspective view.
}

\author{
Ahmad Said Galadanci ${ }^{\mathrm{a}, \mathrm{b},}{ }^{,}$, Anton lanakiev ${ }^{\mathrm{a}}$, Rolands Kromanis ${ }^{\mathrm{a}}$, Julian Robinson ${ }^{\mathrm{a}}$

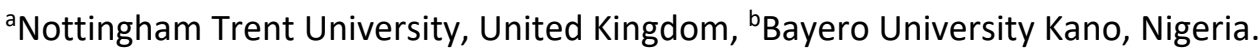

\begin{abstract}
According to the United Nations Global Status Report 2017, buildings and construction account for $36 \%$ of the global energy use and $39 \%$ of energy related carbon dioxide emissions [1]. A prudent design and accurate construction of energy efficient buildings are mandatory to reduce both global energy consumption and carbon dioxide emissions. The desired outcome can be achieved by (i) increasing the construction of low energy buildings, which are designed to sustain desired indoor temperature with a minimal energy input, (ii) and improving the energy performance of existing buildings. Some buildings underperform by gaining or losing more heat than needed. This study introduces a framework for investigating building energy performance. Thermography investigation, building modelling, characterization of thermal bridges and future prediction for overheating are encapsulated in the proposed framework. A sport changing facility, which was designed as a low energy building, serves as a demonstrator for the application of the framework. The energy investigation framework revealed that the facility is underperforming. According to the building model, the main reason for the poor building performance is thermal bridging (presence of steel members), which increases gas consumption and wall heat-loss by $18 \%$ and $11 \%$, respectively. Other contributors to heat lose/gain are cracks in the building envelop, weak mortar joints and uninsulated hot water pipes. Furthermore, the future temperature data, which is input to the building model, suggests that the entire facility is under the risk of overheating.
\end{abstract}

\section{Introduction}

The need to reduce greenhouse gas emissions and increase energy efficiency of buildings has grown in recent years. Effects of climate change can be observed with recent events such as wild fires in Greece and USA, record heat waves around the globe and a four week summer period in the United Kingdom without rain [2]. Researchers have argued that recent heatwaves may evince that the Earth is becoming very sensitive to warming [3]. Since the establishment of the climate change act, building regulations across the world have imposed restrictions for the thermal performance of building envelope. This has led to buildings being designed as low energy buildings, in which minimal energy input is required to sustain desired indoor temperature.

Low carbon policies and increasing costs of energy make society aware of the need for low energy solutions [4]. Around $1 / 3^{\text {rd }}$ of the total energy demand comes from the domestic sector and is responsible for $27 \%$ of all carbon emissions in the United Kingdom [4]. Clark [5] states that it is not an overstatement that designs of new buildings should be improved to reduce the energy consumption 50-75\%. High performance buildings would reduce significantly our nation's energy bill, contribute substantially to the environmental impact and climate change mitigations, and improve building indoor conditions.

Adequately designed building envelopes protect the inner space from harsh outdoor climatic conditions (hot and cold) and provide the necessary thermal comfort to building occupants. This is not necessarily the case in most buildings. Some buildings lose heat or gain unwanted energy from the envelope through thermal bridges. Thermal bridges are critical parts of buildings and envelope areas, in which heat losses are usually higher than through external walls [6]. A thermal bridge is a 
discontinuity in thermophysical properties of the building envelope with reference to the thermal resistance due to material thickness or variations of shape [7] [8]. These are created in building envelopes by repetitive structural members and junctions between different building envelope components [9]. Al-Sanea and Zedan [10] stated that thermal bridges pose the highest threat to almost all measures taken by designers to reduce the energy consumption.

Thermal bridges also pose risks associated with the preservation of structure such as the mould growth and condensation [11]. Even though modern buildings are designed and constructed using highly insulated materials, the performance of buildings is still affected by thermal bridges [12]. Only a few studies have investigated effects of thermal bridges on the performance of the entire building [13]. Thermal bridges are partly neglected or incorrectly used in building energy calculations, and simplified approaches and default values are used instead [14], [15]. De Wilde [16] states that the present gap is too wide to be acceptable, and correctly implementing effects of thermal bridges would reduce the building performance gap between the predicted and measure performances. Thermal losses through the building envelope can be quantified using the incidence factor of the thermal bridge [17]. Thermal bridges may result in the increase of thermal losses through the building envelope to about $9 \%[12]$.

Thermography is a nonintrusive and low-cost solution for building assessment that can be used to detect energy related defects and identify common sources of heat losses such as resulting from conduction and ventilation in existing and new buildings [18]. The assessment of a building system can be implemented through the analysis of each thermogram of surface temperature of objects [17]. Accurate thermograms are obtained, when inputting the correct emissivity factor, reflective and atmospheric temperatures, and relative humidity in a thermal imaging camera. Besides, there should be sufficient difference (at least $10^{\circ} \mathrm{C}$ ) in heat or mass transfer across a material or building fabric (between the inside and outside of the building) [18], [19]. The largest temperature difference during winter and summer periods are at night and day times, respectively.

Computational techniques and computer simulations have been successfully and widely used in the building industry sector [20]. A simulation based design and optimization of building performance can help to reduce energy consumption and environmental impact, and improve the quality of indoor environment [20]. Hong et al [21] state that computer-aided simulations hold the key to improving the building energy efficiency. Computer simulations of building performance are based on iterative processes of understanding and mimicking real world issues [21]. According to Martinaitis et al. [22], the total energy performance of building systems can increase, if computational methods are incorporated in architectural and civil engineering model at the design stage. Finite element (FE) methods are employed to solve the partial differential equation that governs the conduction heat transfer through construction elements of buildings, such as roofs, walls (external and internal) and floors [23].

Energy investigation of buildings helps understanding building performance and achieving anticipated energy efficiency. Previous studies have investigated thermal bridges using experimental set-ups, numerical models and infrared thermography, however, a guided and structured framework for analysing thermal bridging and assessing the risk of overheating is not developed. This study proposes an energy investigation framework to assess building performance by using a systematic transfer of information between the building simulation model, infrared thermography and numerical analysis. The infrared thermography is employed to identify defects related to heat losses and moisture in buildings. The proposed framework is applied to investigate and analyse effects of thermal bridges in a sports changing facility. The risk of overheating in the facility is evaluated using the assessment method recommended by the Chartered Institute of Building Services Engineers (CIBSE). An insight 
supporting the concept of sustainable future buildings is also explored using future weather files from the Prometheus project [24] .

\section{Related work}

An extensive literature review and industry practices related to building energy frameworks and energy analysis is presented in this section. Over the years, building energy frameworks have been created to optimise, analyse, predict and manage building energy performance [25]-[29]. Danish et al [25] proposed a framework which systematically integrates the energy sustainability requirements, together with the corresponding cost assessment for an energy efficient building over its life-span. The study explored innovations in a systematic manner of energy efficient building Implementations, as well as sustainable decision making is preferred to facilitate the conflicting nature of both energy efficiency and management performance indices.

In studying whether insulating dwellings increase overheating risk, Fosas et al [28] developed a framework involving EnergyPlus and Python. Models were validated against data recorded in an apartment and results revealed that insulation plays a minor role in overheating even when comparing un-insulated buildings to super insulated buildings. Furthermore, the authors elaborated that in cases with acceptable overheating levels, the use of improved insulation levels may help in delivering better indoor thermal environments.

Heat loss has a huge impact on the total energy consumed by buildings during operation [30]. Therefore, Najjar et al [30] developed a framework to estimate heat energy loss in building operation. The framework consists of four stages namely performance parameters, Design factors, conceptual framework and visualisation aid. Applying the framework to a single-family house case study, revealed that the total heat energy loss of buildings in tropical and dry climates could reach a value of $16 \%$ to $8 \%$ respectively when compared to moist subtropical mid-latitude climates. However the effects of thermal bridges where not quantified in this study.

A main contributor to heat loss in buildings are thermal bridges. Ascione et al [6] compared results obtained using simplified $1 \mathrm{D}$ models with sophisticated $2 \mathrm{D}$ and $3 \mathrm{D}$ models in order to point out differences in terms of equivalent conductivity and thermal transmittance. Furthermore, three different approaches were used to analyse a thermal bridge represented by a roof structure for a typical office building. It was observed that an over estimation of the heat losses, determined by an approximate evaluation, induces higher cost of refurbishing, higher cooling energy requests in summer and minor thermal comfort in naturally ventilated buildings. Therefore, in conclusion, the outcome of the research showed that a proper modelling is necessary.

Theodosiou and Papadopoulos et al [31] investigated the impact of thermal bridges on the energy demand of buildings by studying a representative wall thermal insulation used in Greek buildings. This wall was observed to be susceptible to the occurrence of thermal bridges, in contrast to a typical thermal insulating façade. Theodosiou and Papadopoulos et al [31] concluded that the existing legislative frame is inadequate, leading to a significant under estimation of actual energy consumption. Furthermore, it was observed that underestimation of thermal losses is more misleading in cases of fully insulated buildings than in the cases of partially insulated ones.

Ramalho et al [32] evaluated the impact of thermal bridges of reinforced concrete structure on the thermal energy performance of a residential building in southern Brazil. This was achieved using three different possibilities to model the thermal bridge in energy plus software. The first approach was to model the building considering the shape of the structure where the thermal bridges occur. The second approach defined as simplified approach was modelled using equivalent wall method. This 
considers only the thermal transmittance of the building's masonry wall. The third approach was similar to the second, but the thermal transmittance of the wall was increased based on the standard EN ISO 10211. Results showed that the third approach has the highest energy consumption when compared to the others as this considers the thermal bridge effect. It was concluded that modelling in the traditional way (approach 2) leads to underestimation of the thermal effect on the energy consumption of buildings.

The use of infrared thermography in buildings has risen over the years with many researchers [19], [33]-[37] applying the technique to analyse the effects of heat losses or gains in buildings. O'Grady, Lechowska and Harte [37] analysed the effect of wind velocity on thermal bridges heat loss using infrared thermography, numerical analysis and experimental study. Results showed that the heat loss from a building surface is influenced significantly by wind velocity with the linear thermal transmittance values increasing with increase in velocity.

\section{Energy Investigation Framework}

The energy investigation framework is a systematic combination of relevant energy analysis methods that provide an all-round investigation into the energy performance of buildings. The framework allows for the detection and analysis of thermal bridging, assessment of overheating risks, and bridges the gap between predicted and measured performance of buildings. The framework (see Figure 1 encompasses the following four phases:

1) Infrared thermography (stead-state analysis),

2) Computer simulation (transient analysis),

3) Effects of thermal bridging,

4) Prediction models.

The framework relies on the systematic transfer of information between the phases (see Figure 2). It commences with the infrared thermography phase, where defects such as thermal bridges are characterized. The computer simulation phase, where an accurate building simulation model is created, is initiated. Essential information from the building plans, monitoring, as well as information from the infrared thermography phase (crack intensities, heat gains and thermal bridges) are used to create an accurate building simulation model. The obtained results are then used to evaluate effects of thermal bridges and generate prediction models using future temperature data, which assesses the risk of overheating. 


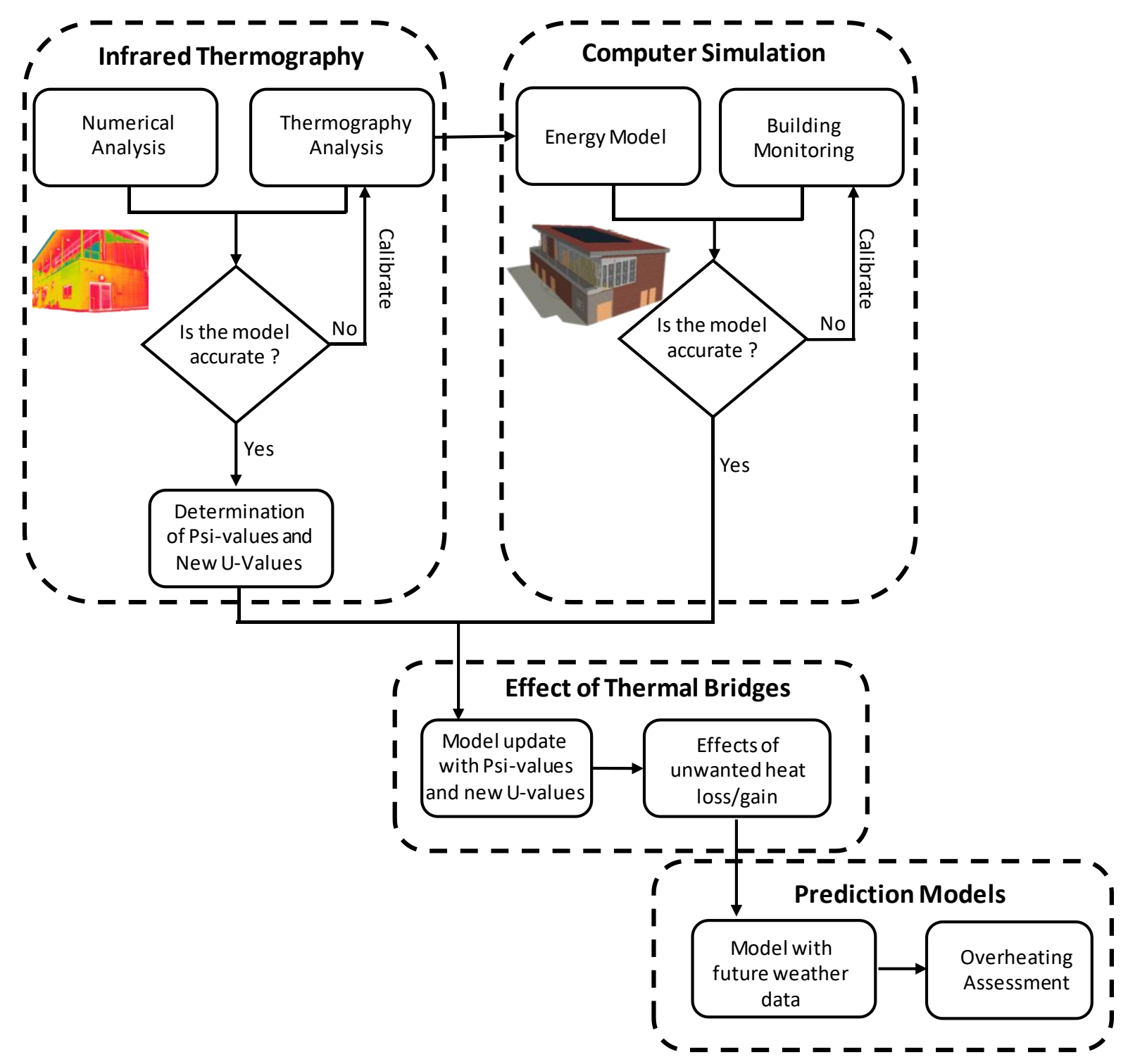

Figure 1: Energy investigation framework.

\section{Steady State Analysis Output}

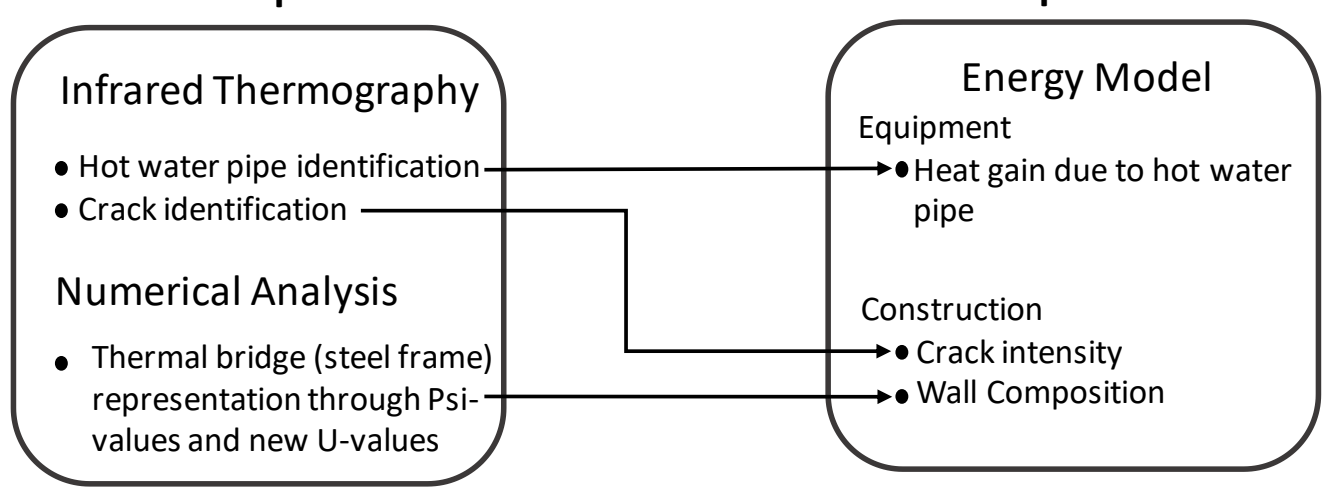

Figure 2: Information/data transferred from steady state analysis to transient analysis.

Transient Analysis

\section{Input}

\section{Energy Model}

Heat gain due to hot water pipe

Construction

Crack intensity

Thermal bridge (steel frame) representation through $P$
values and new $U$-values

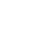
.

\author{
.
}




\subsection{Infrared thermography}

The main objective in the Infrared thermography phase is to detect and evaluate defects within the building envelope. A thermal image provides temperature of each pixel hit by the radiation emitted from the object, i.e., pixels in thermal images are actual temperatures [38]. According to BS EN ISO 9869-8:2018 [39] and BS EN ISO 13187:1998 [40], a thermal imaging camera requires input of the below listed parameters to produce accurate thermal images.

- Emissivity coefficient $(\varepsilon) . \varepsilon$ is found using the reference emissivity method. A material with a known emissivity such as an electrical tape is placed on the surface of another material with unknown emissivity. Using Stephan-Boltzmann law the configuration of the emissivity is changed until the same temperature is obtained and $\varepsilon$ is found.

- Reflected apparent temperature $\left(T_{r e f}\right)$. The reflector method is used to find $T_{r e f}$. A crumpled and re-flattened piece of aluminium foil, which is considered to be a perfect reflector, is placed in the field of view of the infrared camera. $T_{r e f}$ is the temperature of the aluminium foil.

- Atmospheric temperature $\left(T_{a}\right) . T_{a}$ is temperature of a white paper sheet placed at strategic location in the room for 30-60 mins. Any other heat influences (such as lights and equipment) in the vicinity of the sheet must be avoided.

- Humidity and wind parameters are measured with a hygrometer and aneanometer, respectively.

The thermography phase characterizes thermal bridges, crack intensity and heat gains (such as uninsulated hot water pipes). The obtained information is passed as an input to the energy model in the computer simulation phase. Temperature profiles, which are surface temperature drawn in the direction of interest, are obtained from thermal images. Profiles reveal thermal bridges and their extent. Numerical analyses investigate identified thermal bridges with a finite element (FE) analysis. Software such as ANSYS can be employed to carry out analyses, from which the heat flow through the affected areas are analysed. ANSYS is frequently employed for numerical calculations of thermal, hygrometric and kinetic fields [6]. Calculated (FE analysis) and measured (infrared thermography) temperature profiles are compared to validate the accuracy of the FE model. If both profiles have distinguishable differences, the numerical model is calibrated by changing material properties. This is an iterative process and is terminated when a good match between both profiles is achieved. Heat flow values, which are extracted from the FE model, are passed as input values to the effects of thermal bridges phase.

\subsection{Computer simulation}

The computer simulation phase can be initiated only after obtaining data from the infrared thermography phase. The building under consideration is modelled with a building energy simulation software such as DesignBuilder and TRNSYS. Building simulation software use a range of systematic methods to solve the thermal response of building elements. For example, EnergyPlus and TRNSYS use the response factor or transfer function methods, which are the most commonly used in building simulation software [23].

EnergyPlus is a simulation engine based on the features and capabilities of BLAST and DOE-2.1E. Third party modules and interfaces such as DesignBuilder make EnergyPlus an easily usable tool for engineering applications [20]. DesignBuilder enhanced with EnergyPlus is a powerful instrument for modelling building geometries in 3D space and assess their energy performance. DesignBuilder combines rapid building modelling with a dynamic energy simulation [41]. It has been used for analysis, optimisation and evaluation of the energy performance of buildings [22], [42]-[44] 
The building model aims to mimic the building of interest. In an accurate simulation model, input parameters have to match closely the real-life structure. Observations from the thermography analysis such as cracks are input in the energy model. The building monitoring system includes sensors, which collect temperature and other parameters. Collected parameters, especially temperature, are used to validate and calibrate the simulation model. If discrepancies between temperatures from the model and real-world building are significant, the building model is calibrated until indoor temperatures are in a good agreement. The model can then be used to analyse and evaluate the energy consumption of the building.

The model validation describes the extent at which a model produces results that are comparable with alternative or standard methods [45]. Rahman et al [46] emphasized the importance of model validation as an essential task to ensure that the architectural, mechanical and electrical systems are properly modelled together to estimate accurately the energy performance of the building. Three methods, (i) empirical validation, (ii) analytical verification, (iii) and inter-model comparison, are employed to test the performance of building energy calculation methods and software [45].

Theodeousiou et al [31] conveyed the importance and need for the convergence between the predicted and actual building energy consumption, which is an essential factor that needs to be considered at the building design and construction. The validation process can be done with monthly and hourly measurements. Recommendations for the allowable difference between the predicted and measured data are $5 \%$ and $15 \%$ for monthly and daily comparisons, respectively [46]. Building models seldom perform as real-world buildings even when sophisticated energy simulation methods are built [22]. Therefore, if the simulated model exceeds recommended indices, the model calibration takes place. In the model calibration, the objective is to tune the model to obtain results that are similar to the real-world building. This involves adjusting occupancy and HVAC schedules.

\subsection{Effects of thermal bridges}

The effect of thermal bridges phase analyses the influence of thermal bridges on the building energy performance. Output data from the infrared thermography phase and computer simulation phase is input to the this phase. The heat losses $\left(H_{D}\right)$ (obtained from the thermography analysis) is used to calculate the linear thermal transmittance of the thermal bridge using Equation (1) from EN ISO 10211 [7].

$$
H_{D}=\sum_{i} U_{i} A_{i}+\sum_{k} \Psi_{k} l_{k}+\sum_{j} \chi_{j}
$$

where $U_{i}$ and $A_{i}$ are $U$-value and cross-section area, respectively, of $i^{\text {th }}$ material, $\Psi_{k}$ and $l_{k}$ are the linear transmittance and affected length, respectively, of $k^{\text {th }}$ thermal bridge, and $\chi_{j}$ is the $j^{\text {th }}$ point of thermal transmittance.

BRE Digest 465 [47] gives many formulas to calculate the $U$-value of different wall types such as an external wall of a steel frame structure. BRE Digest 465 [47] introduces a parameter $(p)$ (see Equation $(2))$, which depends on spacing between the steel studs $(s)$ and their depth $(d)$ in the wall construction.

$$
p=0.8\left(\frac{R_{\min }}{R_{\max }}\right)+0.32-0.2\left(\frac{600}{s}\right)-0.04\left(\frac{d}{100}\right)
$$

where $R_{\max }$ and $R_{\min }$ are upper and lower resistance limits, respectively. The resistance limits can be obtained using equations (3) and (5)

$$
\frac{1}{R_{\max }}=\frac{f_{a}}{R_{T a}}+\frac{f_{b}}{R_{T b}}+\cdots+\frac{f_{n}}{R_{T n}}
$$


where $R_{T a}, R_{T b}, \ldots \ldots . ., R_{T n}$ are total thermal resistances for each section and $f_{a}, f_{b}, \ldots \ldots ., f_{n}$ are the fractional areas of each section.

$$
\frac{1}{R_{j}}=\frac{f_{a}}{R_{a j}}+\frac{f_{b}}{R_{b j}}+\cdots+\frac{f_{n}}{R_{n j}}
$$

where $R_{j}$ is the equivalent thermal resistances for each thermally inhomogeneous layer.

$R_{\text {min }}$ is determined using equation (5).

$$
R_{\text {min }}=R_{s i}+R_{1}+R_{2}+\cdots+R_{n}+R_{s e}
$$

where $R_{s i}$ and $R_{s e}$ are the internal and external surface resistance, respectively.

The value of total resistance $\left(R_{T}\right)$ is obtained from Equation (6) and the corresponding $U$-value, later used in Equation (1), is obtained from Equation (7).

$$
\begin{aligned}
& R_{T}=p R_{\max }+(1-p) R_{\text {min }} \\
& U=\left(\frac{1}{R_{T}}\right)+\Delta U_{g}+\Delta U_{f}
\end{aligned}
$$

where $\Delta U_{g}$ and $\Delta U_{f}$ are corrections for air gap and fixings, respectively.

The additional change in the $U$-value due to the air gap and steel fixings are given in Equation (8) and Equation (9).

$$
\Delta U_{g}=\Delta U^{\prime \prime}\left(\frac{R_{l}}{R_{t}}\right)^{2}
$$

where $R_{l}$ is the thermal resistance of the layer containing air gaps, $R_{t}$ is the total thermal resistance, which the element would have in the absence of air gaps and fixings, and $\Delta U$ " is the air gap correction factor as defined in BS EN ISO 6946 [48].

$$
\Delta U_{f}=\propto \lambda_{f} A_{f} n_{f}\left(\frac{R_{f}}{R_{T}}\right)^{2} / d_{f}
$$

where $\lambda_{f}$ is the thermal conductivity of the fixing, $A_{f}$ is cross-sectional area of the fixing, and $n_{f}$ is number of fixings per square metre.

\subsection{Overheating Assessment}

Predictive models are accurate only if the models perform as expected. The energy investigation framework in this case is used to assess the risk of overheating using CIBSE Guide A [49] and TM52 overheating assessment guides. According to CIBSE Guide A, a building is overheated when the operative temperature exceeds benchmark temperatures. Some benchmark temperatures are summarized in Table 1

If the temperature is above the benchmark for a longer period than the designated amount of time, which is $1 \%$ of the annual occupied hours, the building is overheating. CIBSE TM52 overheating criteria considers both number of occurrences and the length of time of high temperatures. Overheating is defined by three criteria that provide a robust and balanced assessment of buildings: (1) Hours of 
Exceedance, (2) Daily Weighted Exceedance, (3) and Upper Limit Temperature. A building is regarded as overheated if it fails two overheating criteria.

Table 1: Benchmark temperatures from CIBSE Guide A

\begin{tabular}{lcc}
\multicolumn{1}{c}{ Building Type } & $\begin{array}{c}\text { Bench mark summer } \\
\text { peak temperature }{ }^{\circ} \mathrm{C}\end{array}$ & Overheating criteria \\
\hline Offices & 28 & $1 \%$ annual occupied hours over \\
Schools & 28 & operative temperature of 28 \\
Residential (living areas) & 28 & $1 \%$ annual occupied hours over \\
Residential (Bedrooms) & 26 & operative temperature of 26 \\
\hline
\end{tabular}

Criteria 1: Hours of exceedance sets a limit for the number of hours that the operative temperature can exceed the upper limit of comfort temperature by $1^{\circ} \mathrm{C}$ or more during the occupied hours of a typical non-heating season (typically between 1 May to 30 September). The temperature difference $(\Delta T)$ between the operative temperature $\left(T_{o p}\right)$ and limiting maximum acceptable temperature $\left(T_{\max }\right)$ is calculated as:

$$
\Delta T=T_{o p}-T_{\max }
$$

Criteria 2: Daily Weighted Exceedance sets an acceptable level for the severity of overheating according to BS EN 15251, Degree hours criteria Annex F Method B. This is the time during which the operative temperature exceeds a specified range of hours when the building is occupied.

Criteria 3: Upper Limit Temperature sets a limit after which normal adaptive actions would be insufficient to restore personal comfort and occupants would complain of living area being too hot. The $3^{\text {rd }}$ criteria covers the extreme hot weather condition and future climate scenarios.

\section{Application of Building Energy Framework}

Nottingham Trent University (NTU) is committed to create a sustainable campus by investing in its buildings, environment and spaces. Some existing buildings are renovated and new ones are built to comply with low energy building standards. The Pavilion Building, for example, after renovation generates more energy than it consumes and has an A+ rating. However, some new low energy buildings with both passive and active energy measures such as the Clifton Clubhouse, which is selected in this study to demonstrate the application of the framework, are underperforming. The clubhouse is a two-storey building, oriented in the North direction, and located at NTU Clifton campus, near Nottingham, UK (see Figure 3). Nottingham is a $74.61 \mathrm{~km}^{2}$ city located in the East Midlands with latitude of $52.955^{\circ} \mathrm{N}$, longitude of $1.157^{\circ} \mathrm{W}$ and altitude of $117 \mathrm{~m}$. The climate in Nottingham is warm and temperate with significant rainfall. The Köppen-Geiger classification of Nottingham is Cfb (warm temperate, fully humid and warm summer). 


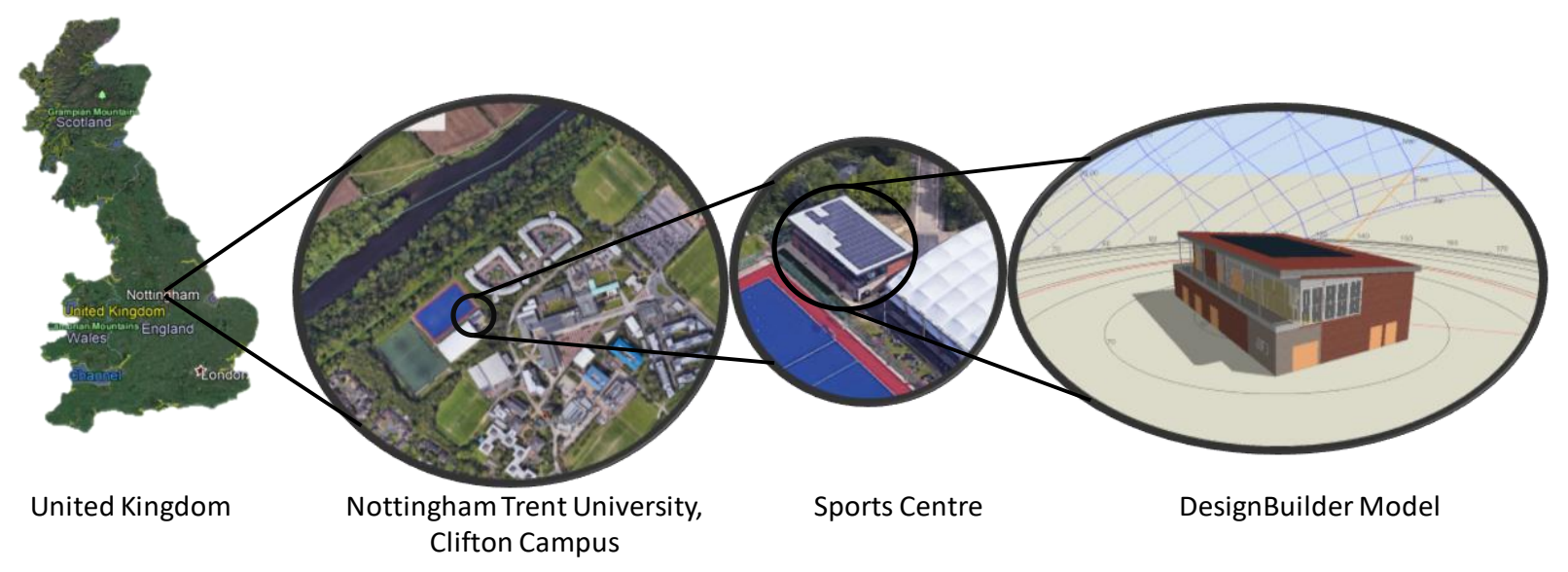

Figure 3: Clifton Clubhouse. Left to right: location in the UK, location and orientation in the campus, bird's view and DesignBuilder model.

The clubhouse, which has a changing facility with showers and a lounge, is mainly used during the study period. The ground floor is composed of showers, the entrance lobby to the first floor, and changing, storage and plant rooms. There are two changing rooms with showers and the main lounge in the first floor. The floor plans of the clubhouse are provided in Figure 4. The external walls have thermal resistance of $3.07 \mathrm{~m}^{2} \mathrm{k} / \mathrm{W}$, which gives a $U$-value of $0.326 \mathrm{~W} / \mathrm{m}^{2} \mathrm{~K}$. Table 2 provides summary of the building information and main parameters including the construction of the external wall and internal partitions.
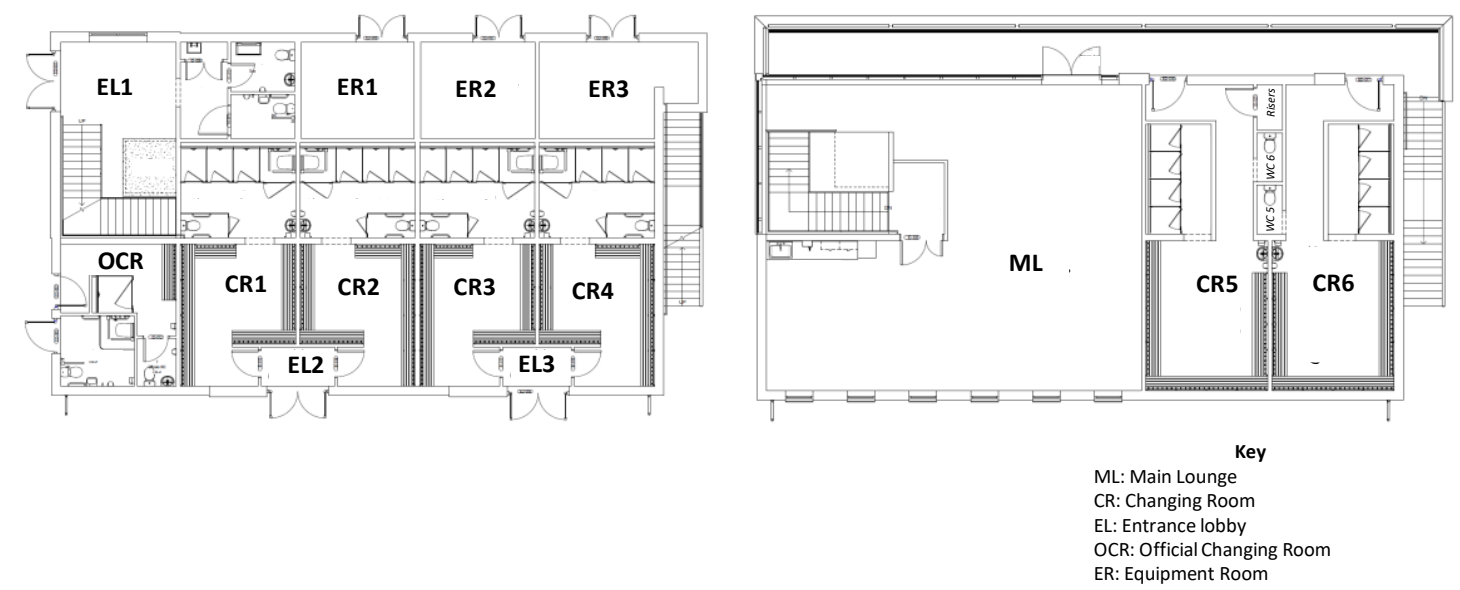

Figure 4:Ground floor (left) and first floor (right) of the clubhouse 
Table 2: Building description

\begin{tabular}{|c|c|c|}
\hline Building location & Nottingham Trent University & Nottingham, United Kingdom \\
\hline \multirow{5}{*}{$\begin{array}{l}\text { Building type } \\
\text { Floor area } \\
\text { Dimensions and height }\end{array}$} & Sports lounge & \multirow{5}{*}{$\begin{array}{l}\text { Changing facility } \\
450.9 \mathrm{~m}^{2} \\
3.5 \mathrm{~m} \\
1.0 \mathrm{~m} \\
2.1 \mathrm{~m}\end{array}$} \\
\hline & Occupied floor area & \\
\hline & Average floor height & \\
\hline & Window Height & \\
\hline & Door height & \\
\hline \multirow[t]{4}{*}{$\begin{array}{l}\text { Construction and building } \\
\text { envelope }\end{array}$} & External wall & $\begin{array}{l}102.50 \mathrm{~mm} \text { Old Trafford Red brick } \\
75 \mathrm{~mm} \text { Knauf Dritherm Cavity Slab } \\
140 \mathrm{~mm} \text { Thermalite Hi Strength }\end{array}$ \\
\hline & Roof & $\begin{array}{l}\text { Solar panel } \\
\text { Roofing sheets }\end{array}$ \\
\hline & Partition & $\begin{array}{l}\text { Hanson Evalast Paint Grade } \\
\text { Aggregate }\end{array}$ \\
\hline & Windows & Double glazed clear \\
\hline \multirow[t]{3}{*}{ Operating hours } & Monday to Friday & $8: 00 \mathrm{hrs}$ to $17: 00 \mathrm{hrs}$ \\
\hline & Weekend & Closed \\
\hline & Holiday & Closed after term time \\
\hline \multirow[t]{2}{*}{ Lights } & Type & Surface mount \\
\hline & Target Illuminance & $200 \operatorname{lux}$ \\
\hline \multirow[t]{2}{*}{ Activities } & Occupancy schedule & $\begin{array}{l}\text { University changing facilities with } \\
\text { showers }\end{array}$ \\
\hline & Activity & Changing facility with showers \\
\hline Domestic hot water & Type & Gas boilers \\
\hline Solar panel & Capacity & $34 \mathrm{~kW}$ \\
\hline
\end{tabular}

The clubhouse has natural ventilation in the main lounge with air exchangers in the showers and changing rooms. The air exchange rate of the building is kept constant during occupancy hours. The building is equipped with $34 \mathrm{~kW}$ solar panels. The main lounge is cooled using natural ventilation from glazing. Both floors are heated with natural gas. Changing rooms and showers are equipped with heat recovery units.

\subsection{Infrared Thermography}

The thermography survey was carried out on the $26^{\text {th }}$ of November 2017 at 20:00 hrs, when outside was dark and cold, using FLIR T600. The survey reveals hot water pipes and cracks in the wall. Exposed domestic hot water pipes contribute significantly to heat gains in the changing rooms (see Figure 5 (top)). Convective and radiative heat transfer mechanisms generate heat gains in the room. The trapped air creates a convective transfer mechanism when released into the room through the heat recovery unit, while hot pipes introduce the radiative heat transfer. The delivery temperature of hot water in the pipes is $55-60^{\circ} \mathrm{C}$. The heat emitted from the hot water pipe through natural convection and radiation were calculated as $11.47 \mathrm{~W} / \mathrm{m}^{2}$ and $30.28 \mathrm{~W} / \mathrm{m}^{2}$, respectively. Cracks in the building envelope affect indoor temperature (see Figure 5 (bottom)). Cracks provide a pathway for heat gain in the internal wall as the other side of the wall (i.e. main-lounge) is has higher temperatures. Mortar joints, on the other hand, add heat gains into the rooms. This information/data is used as input into the energy model (See Figure 2). 

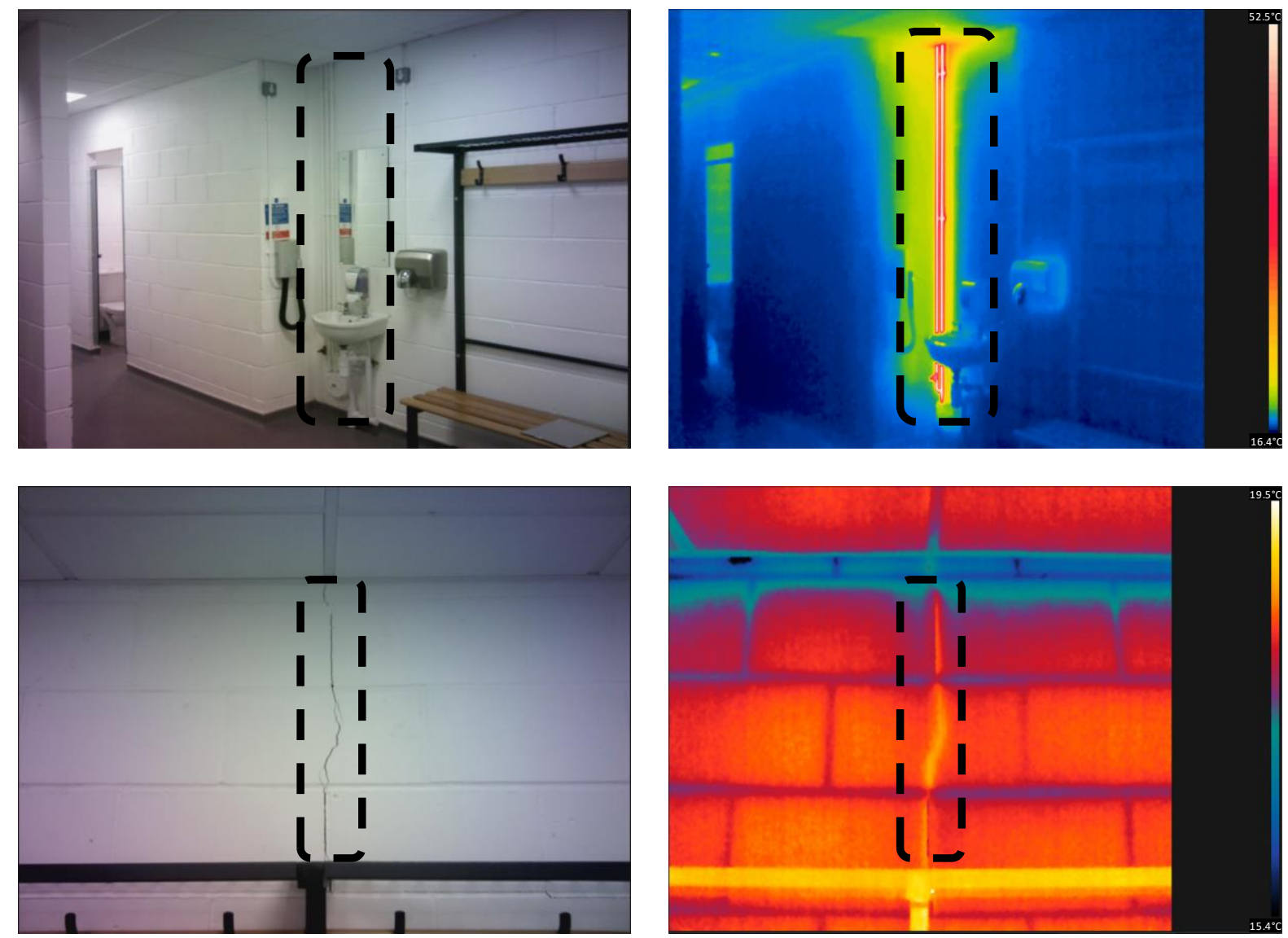

Figure 5: Digital (left) and thermal (right) images of defects in changing rooms: a hot water pipe (top) and crack (bottom).

Temperature profiles with thermal bridges are analysed to determine the extent of heat losses and/or gains in the clubhouse. Three temperature profiles of the external walls are analysed (see Figure 6). Temperature difference between blocks and expansion joint (with steel member) is approximately $1.2^{\circ} \mathrm{C}$ (see Figure $6(\mathrm{a})$ ). Temperature within the expansion joint is undulating and decreasing at every intersection of mortar joint (Figure 6(b)). Temperature of the adjacent external wall reduce from the top to bottom to its centre (Figure 6(c)). Marginal variations in temperature are observed at mortar joints.
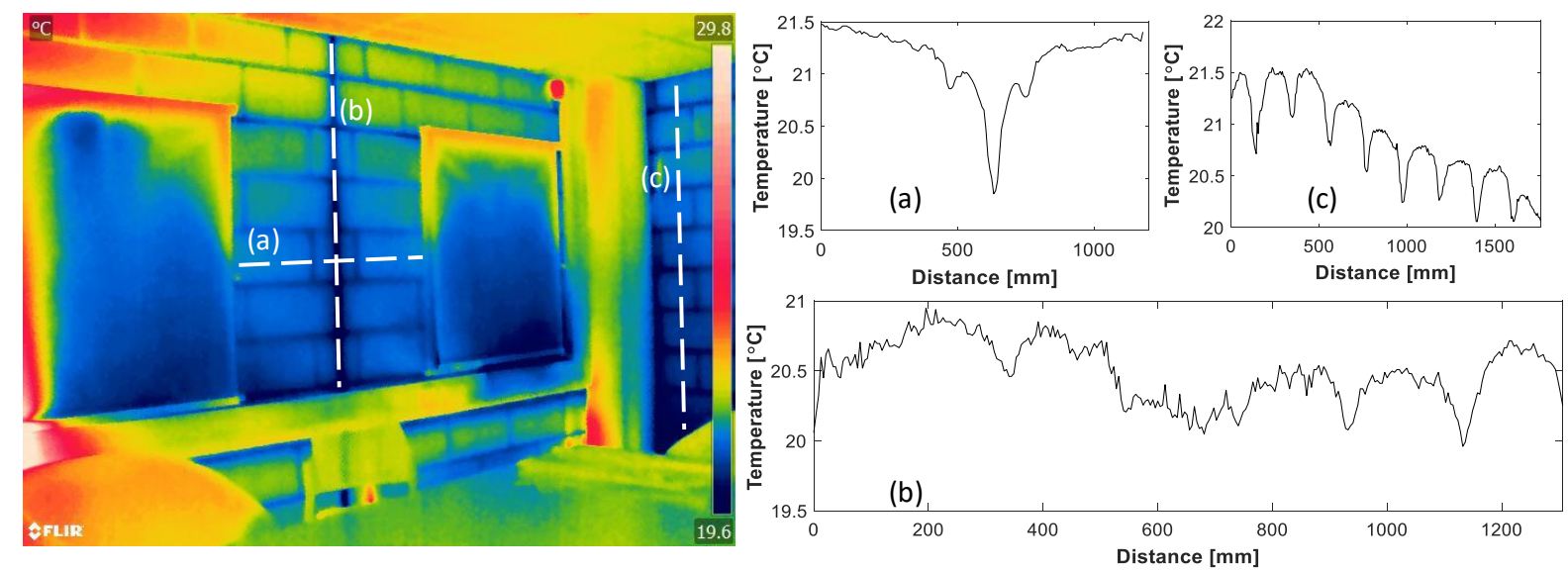

Figure 6: Thermal image (left) with corresponding temperature profiles. 


\section{Numerical analysis and model validation}

The numerical analysis aims to obtain the heat flow through thermal bridges and examines their effects. Locations of thermal bridges revealed in the thermography analysis are investigated. Measured parameters such as temperatures during the thermography are input to the FE model in Ansys. Temperature profiles are generated from simulations and compared with profiles obtained in the thermography analysis. The convection heat transfer, heat transfer coefficient and bulk temperatures are applied to both internal and external layers of the wall. These are set as constant variables to simulate the same conditions as observed in the infrared thermography analysis.

Walls observed to have defects are modelled according to the wall construction shown in Figure 7. Thermal mass Brick and node 8 - SOLID 278 [50], which has a 3D thermal conduction capability, is used to model brickwork, blockwork, mortar, thermal insulation and steel members. This element has eight nodes with a single degree of freedom. Temperature is input at each node. The element is applicable for 3D steady state or transient analysis. Thermal conductivity, specific heat and density of the material are used as input to define the thermal behaviours.

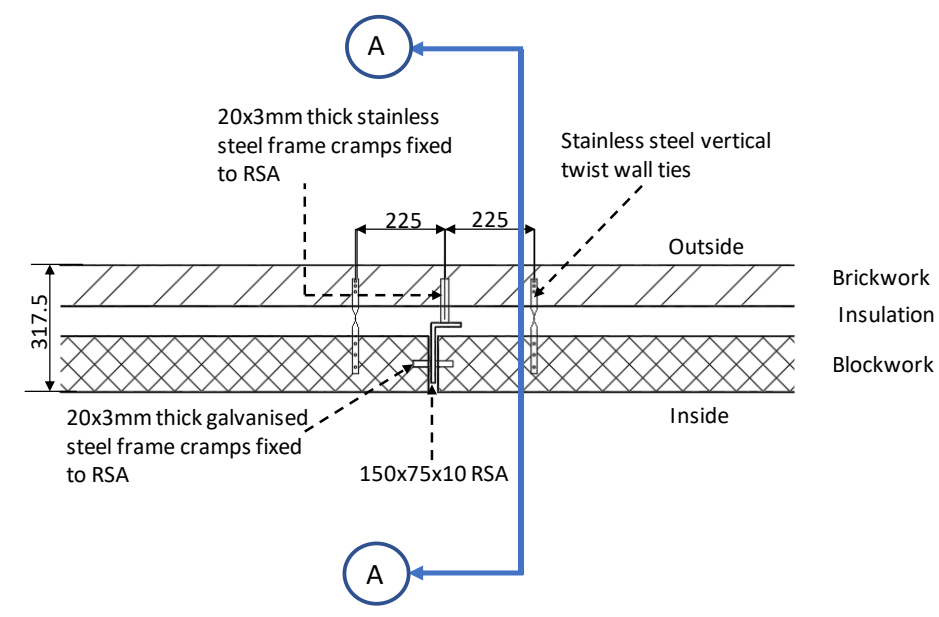

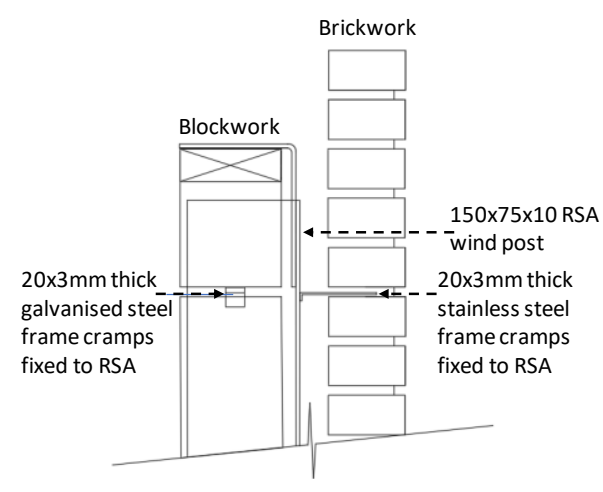

Section A-A

Figure 7: Wall plan (a) and section A-A (b)

The numerical analysis is simulated with steady state conditions applying the indoor and outdoor temperatures. Temperature profiles are calculated using path operations, in which nodal temperatures and distances between nodes are found. Numerical models of the mortar and expansion joints are shown next to the corresponding thermal images in Figure 8. Thermal bridges are discernible in both numerical models and thermal images. Simulated and measured temperature profiles of both joints are shown in Figure 9. The plots of simulated and measured temperatures are in a very good agreement. Deviations in temperature profile are due to the material properties used in the model are assumed to be homogeneous and isotropic which is not the case in reality. Furthermore, the thermal properties used in the model were obtained from building plans and may not be as accurate. 

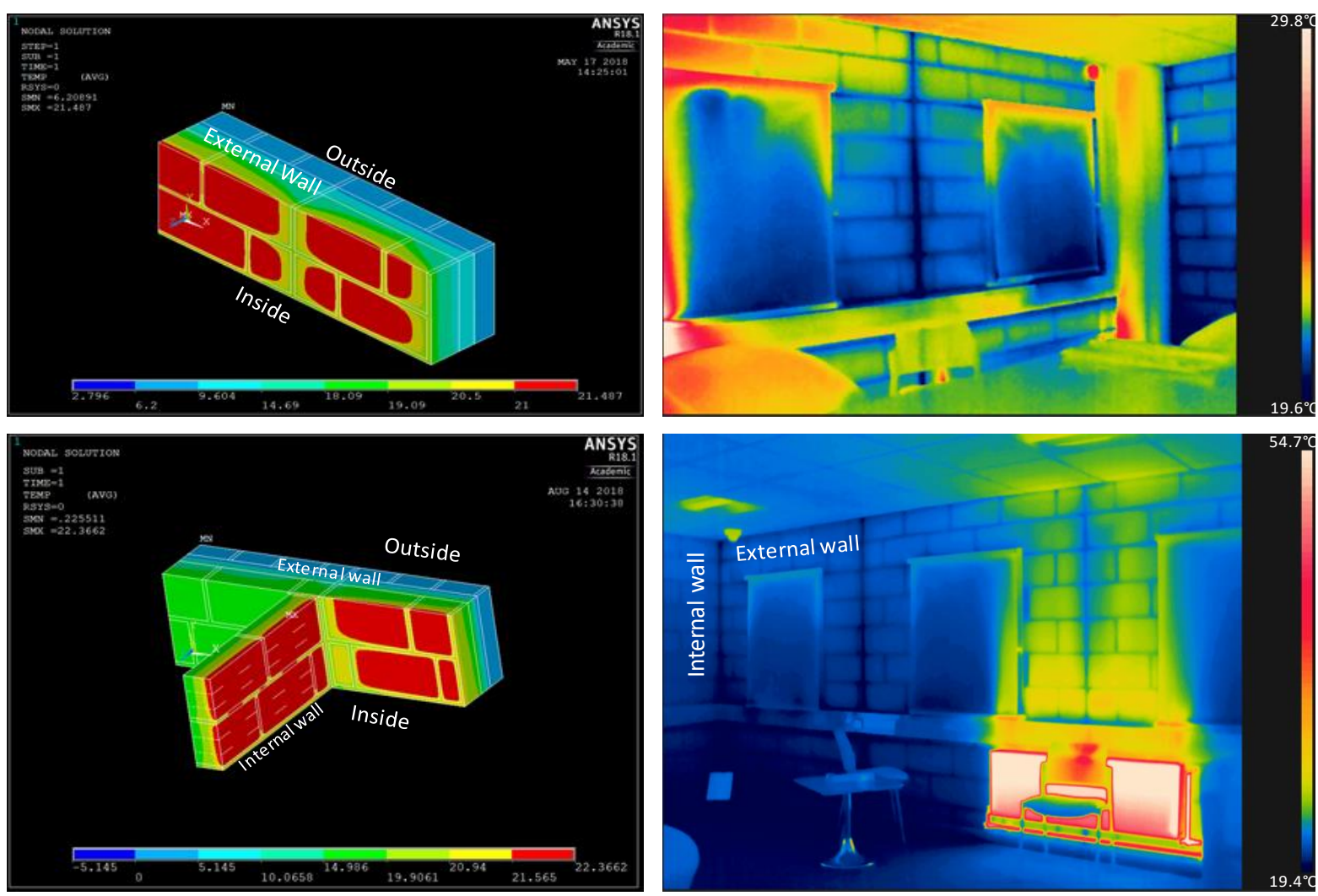

Figure 8: Numerical models (left) and corresponding thermal images (right) of expansion (top) and corner joints (bottom).
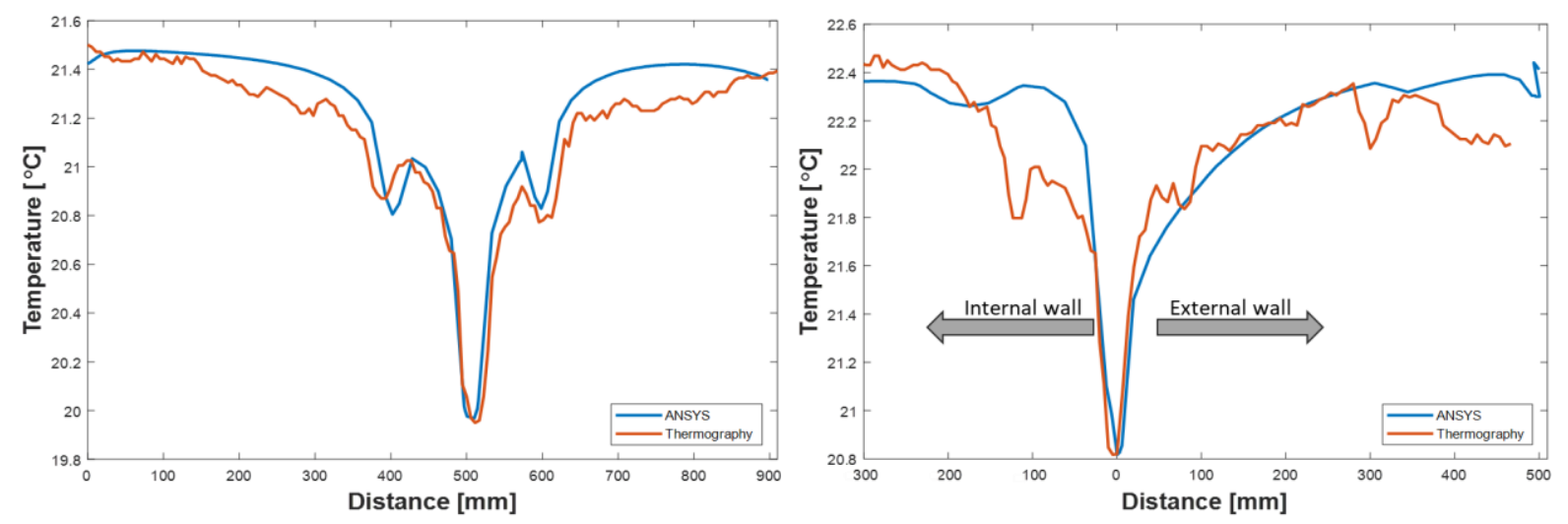

Figure 9: Simulated (ANSYS) and measured (thermography) temperature profiles at the expansion (left) and corner (right) joints

\subsection{Computer simulation}

The model of the clubhouse (see Figure 3 (right)) is developed using DesignBuilder. The properties of the building are modelled using information provided in Table $\mathbf{2}$. The model is divided into three zones. Zone 1 is the changing rooms with showers. Zone 2 is the main lounge. Zone 3 , which is set to be unoccupied, is the lift area and roof, which are neither heated nor cooled. The HVAC system is simulated using a sophisticated model of HVAC system. The building is divided into three zone groups for modelling the HVAC system. The heating using a boiler system is modelled and applied to the zone group 1, which encompasses the main lounge and reception, where heating is available. The domestic 
hot water system is applied to zone group 2, which comprises the main lounge, changing rooms, showers and toilets. The delivery set-point temperature is set to $55^{\circ} \mathrm{C}$ as observed in the thermography survey. The heat recovery unit is modelled with an inlet and extraction fans in zone group 3, which consist of the changing rooms and showers.

As mentioned in section 2.1 and 2.2, information is collected from the thermography survey and passed as input into the energy model. Due to the presence of cracks on both internal and external walls, the crack intensity in the energy model was set as medium. Also heat gains from the observed uninsulated hot water pipes into the changing rooms were calculated and set as input. This was done for both convective and radiative heat transfer mechanisms. The schedule of the usage of the hot water pipe was also set in the energy model.

Weather data are essential for all energy simulations. The weather data for Nottingham is obtained from the UK Met office [51]. This complies with ASHREA [52], where the source of weather data shall be the nearest available weather station, when on site measurements are unavailable. Figure 10 shows the dry-bulb temperature at Nottingham from July 2017 to July 2018. Temperature in summer 2018 is higher than in summer 2017. This was due to the heatwave experienced during the summer of 2018 [2].

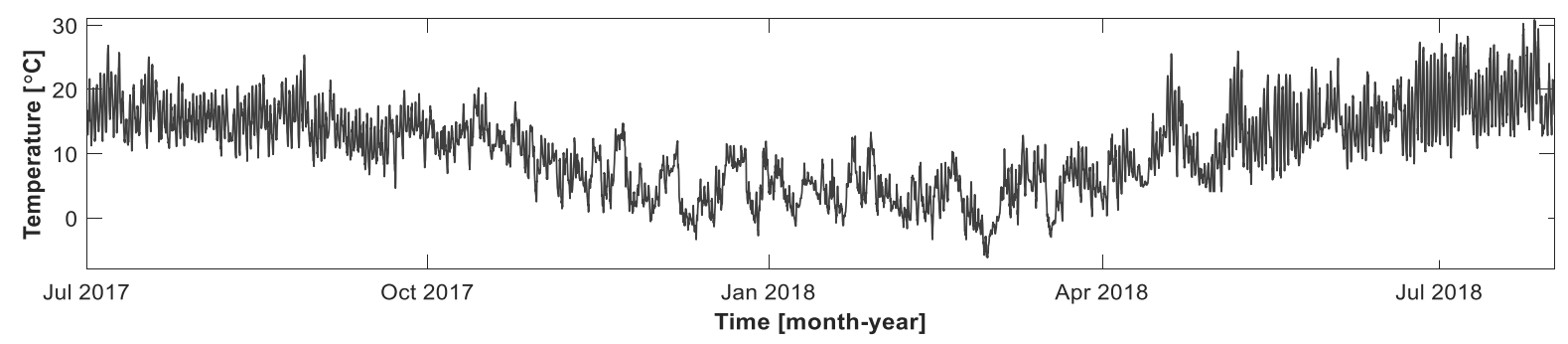

Figure 10: Dry-bulb temperature data for Nottingham between July 2017-July 2018

Three Log Tag Haxo-8 humidity and temperature sensors collect indoor temperature in the main lounge and two changing rooms. The sensor can capture up to 8000 measurement sets of relative humidity and temperature within 0 to $100 \%$ and $-40^{\circ} \mathrm{C}$ to $+85^{\circ} \mathrm{C}$ range, respectively. Sensors are installed in strategic locations to avoid direct influence of HVAC systems, other electric appliances and direct heat source or light. In this study, temperature measurements collected at 15 minute intervals for a period of one year. The temperature sensors are were placed in the close to the ceiling to avoid the sensors being tempered by the users of the facility.

\section{Model Validation}

Operative temperatures from the simulation model and sensors are compared for the main lounge and two changing rooms. Time histories of hourly temperatures are considered for the model validation. Figure 11 shows temperatures from the model and sensors. The building simulation model gives fairly comparable temperatures to the real-world building. Temperatures do not match perfectly, which is also observed in other studies [22]. The absolute difference between monthly temperatures in the selected areas is $9 \%$, which is within the allowable difference [46]. The monthly root mean square error (RMSE) ranges from 0.078 to $1.451{ }^{\circ} \mathrm{C}$ in the main-lounge, while a range of 0.022 to $2.169^{\circ} \mathrm{C}$ in the changing room. However, the monthly coefficient of variance of RMSE (CVRMSE), which relates RMSE to the range, varied from $0.44 \%$ to $5.00 \%$ for the main-lounge and $0.34 \%$ to $9.36 \%$ in the changing room. CVRMSE values comply well with the threshold set by ASHREA14 [52] confirming the validity of the model. 


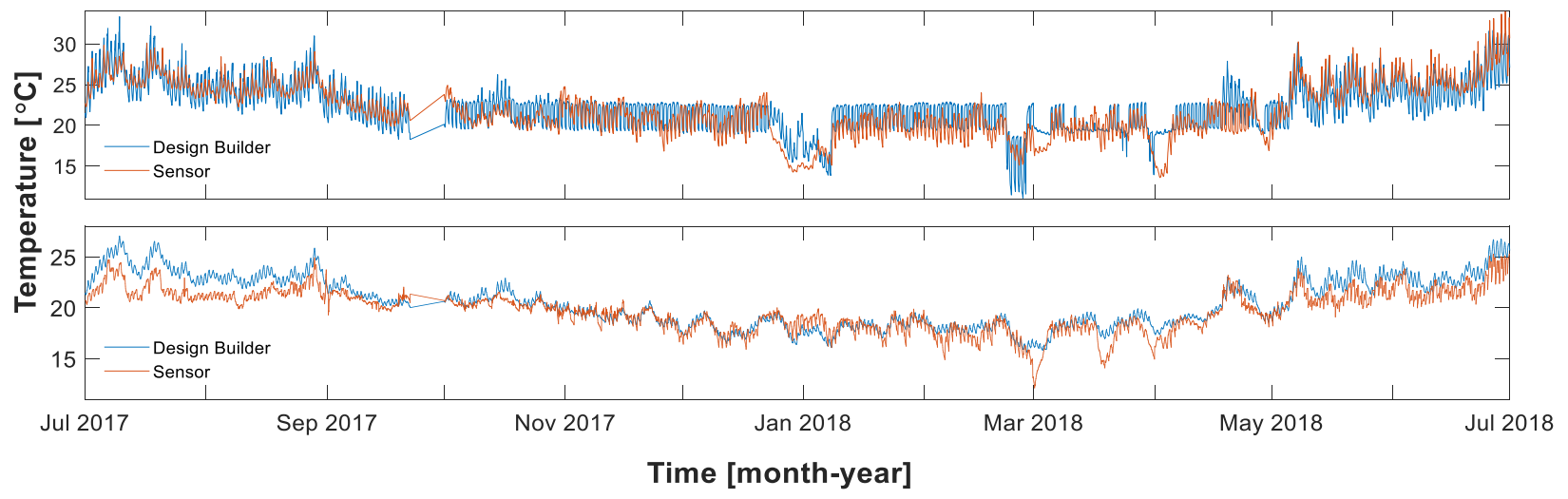

Figure 11: Comparison between sensor and DesignBuilder for the main lounge (top) and changing room (bottom)

Temperature discrepancies can be attributed to the fact that building energy simulation software fails to quantify the uncertainty in human activities and interactions with the building [22], [53]. In the main lounge, a natural ventilation, which relies on the occupant interaction, is used. The natural ventilation also contributes to the increase of discrepancies between the model and real building [54]. All of the above results in modelling errors for low energy buildings, which use passive designs such as natural ventilation.

A monthly comparison of the utility consumption between the simulation model and real-world building is given in Figure 12. The CVRMSE for the electricity and gas consumptions are $7 \%$ and $8 \%$, respectively. The highest consumption is during winter. In summer the changing facility is not used, hence there is very little gas consumption. However, the electricity consumption is the highest during summer due to the main-lounge being used for summer school classes. The building model is concluded to be valid and capable of producing fairly accurate operating conditions of the clubhouse.

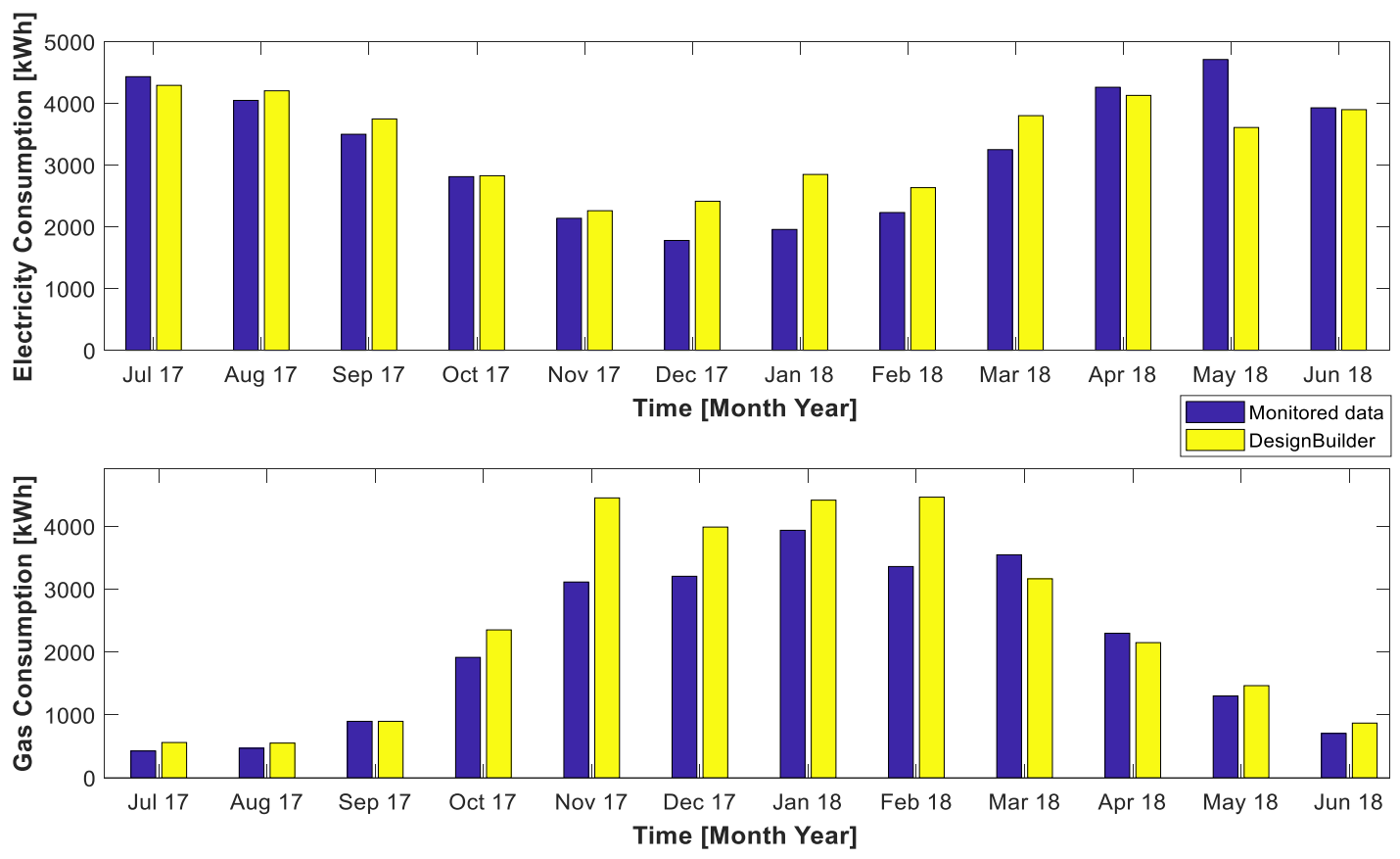

Figure 12: The comparison of electricity (top) and gas (bottom) consumptions between the real data from the clubhouse and simulated model. 


\subsection{Effects of thermal bridging}

The heat flux through the envelope is extracted from the numerical analysis. From this data, the effect of thermal bridges on the energy consumption is calculated. Heat flux profiles illustrate that the heat passing through (i) the expansion and mortar joints is $27.54 \mathrm{~W} / \mathrm{m}^{2}$ and $15.9 \mathrm{~W} / \mathrm{m}^{2}$, respectively (Figure 13 (left)), and (ii) the corner joint is $55.1 \mathrm{~W} / \mathrm{m}^{2}$ (Figure 13 (right)).
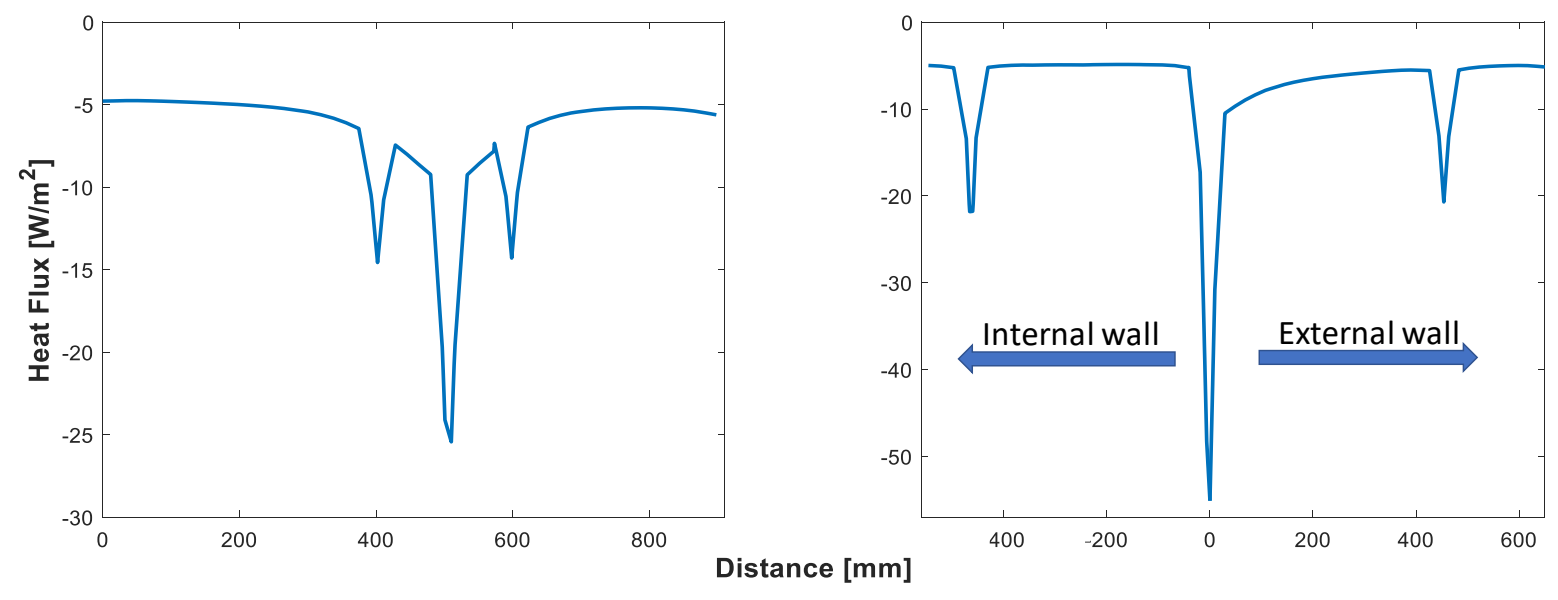

Figure 13: Heat flux profile of expansion joint (left) and corner (right)

Thermal bridges are observed to develop around steel frames. The detail of the envelope is shown in Figure 7. The corresponding $U$-values and psi-values are calculated using Equations (1) to (6) (see Section 2 and Table 3). The $U$ - and psi-values are input into the building model to compute the annual energy consumption with and without thermal bridges. It should be noted that due to EnergyPlus use of transfer functions, DesignBuilder provides an interface where thermal bridge can be specified in the construction (through specification of the material properties) and the Psi-values in terms of linear thermal transmittance. Other methods that can be used to specify thermal bridges include the equivalent wall method. An increase of $18 \%$ of the annual gas consumption is observed for the model in which thermal bridges are removed (Figure 14 (bottom)). The highest gas consumption difference ( $36 \%$ ) is between the models with and without thermal bridges for winter months, while there is only $5 \%$ difference is in June. This is attributed to difference in the external and internal environments and building occupancy. Figure 14 (top) shows the heat loss through external walls. When thermal bridges are removed the heat loss reduces by $11 \%$ and $2 \%$ during winter and summer, respectively.

\section{Table 3: Thermal bridge properties}

\section{Thermal Bridge Location}

Thermal bridge created by the steel frame

Thermal bridge created at the corner junction

\begin{tabular}{ccc} 
U-Value & New U-Value & Psi-Value \\
\hline 0.32 & 0.52 & 0.256 \\
0.32 & 0.32 & 0.678
\end{tabular}




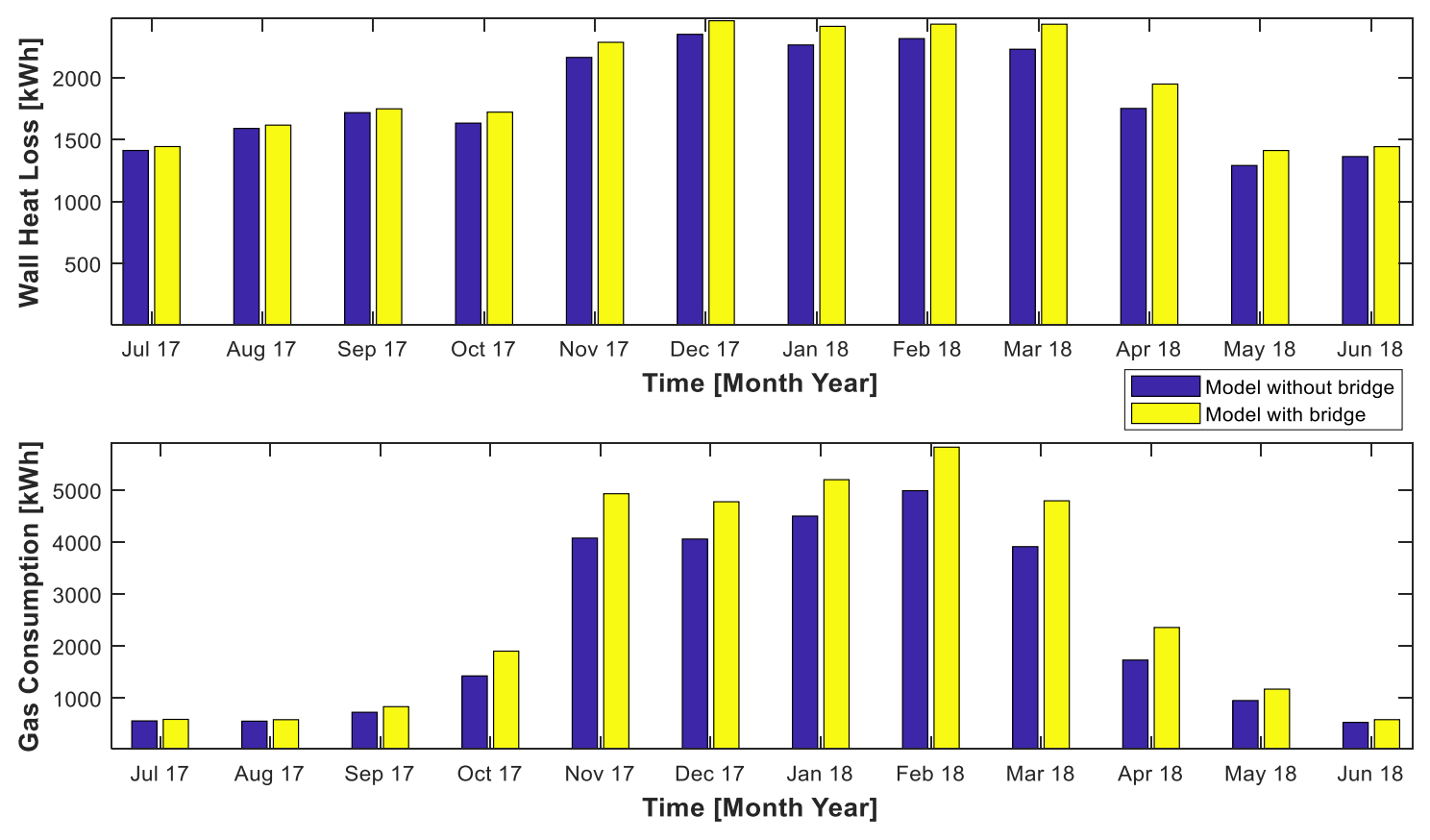

Figure 14:Effect of thermal bridges: annual gas consumptoin (top) and heat loss through the wall in a steel fram (bottom)

\subsection{Overheating Assessment}

For low energy buildings with passive and active energy measures, cooling within the building envelope is assumed only via the natural ventilation. In 2018, the United Kingdom has experienced the effect of climate change with the ambient temperature raising above $30^{\circ} \mathrm{C}$ during the daytime for an extended period. The risk of overheating for the future years is predicted for the clubhouse using the CIBSE Guide A criteria and CIBSE TM52 overheating assessment methods. Future weather data for Nottingham is obtained from the Prometheus Project [24]. Time histories of predicted daily temperatures in summer (from May to end September) 2030, 2050 and 2080 are shown in Figure 15. These periods are simulated for the overheating assessment, as specified in both CIBSE Guide $A$ and TM52. Assessment results are presented in Table 4. For the year 2030 and 2050, the main lounge and entrance have failed all three criteria. This is due to the main-lounge and entrance being cooled only by natural ventilation. An increase of $29 \%, 31 \%$ and $78 \%$ on the criterion 1 to 3 values, respectively, are observed between 2030 and 2050 in the main-lounge. The changing rooms are risk free due to the availability of mechanical ventilation. 


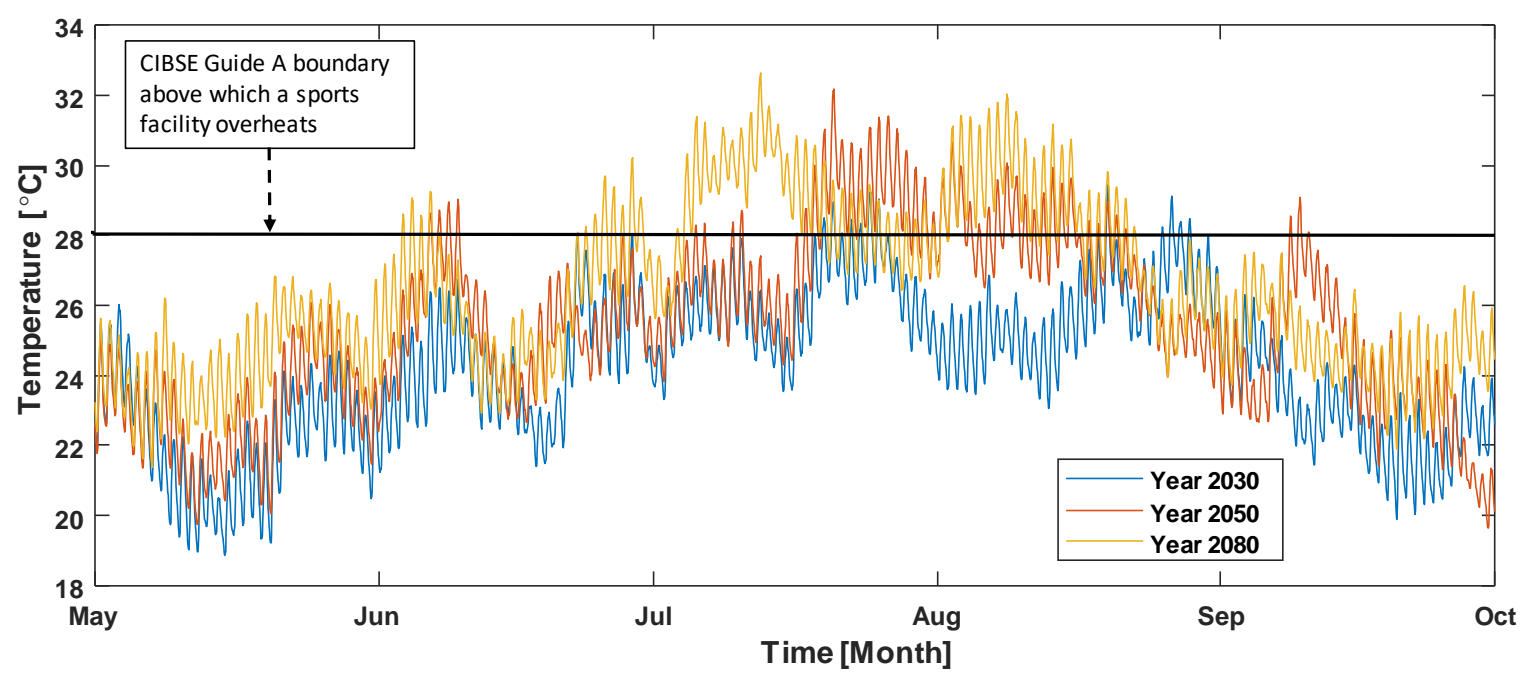

Figure 15: Future temperature predictions in Nottingham.

Table 4: CIBSE TM52 Assessment method for the year 2030 and 2050, 50 ${ }^{\text {th }}$ percentile

\begin{tabular}{|c|c|c|c|c|c|c|c|c|}
\hline \multirow[b]{2}{*}{ Zone/Year } & \multicolumn{2}{|c|}{ Criterion 1 (\%) } & \multicolumn{2}{|c|}{ Criterion 2 (Khr) } & \multicolumn{2}{|c|}{ Criterion 3 (hr) } & \multicolumn{2}{|c|}{ Pass/Fail } \\
\hline & 2030 & 2050 & 2030 & 2050 & 2030 & 2050 & Y.2030 & Y.2050 \\
\hline F1 Changing rooms & 0.0 & 0.0 & 0.0 & 0.0 & 0.0 & 0.0 & & iss \\
\hline Main lounge & 30.2 & 42.2 & 67.0 & 97.5 & 40.0 & 182.5 & & ail \\
\hline GF Changing room & 0.0 & 0.0 & 0.0 & 0.0 & 0.0 & 0.0 & & iss \\
\hline Entrance lobby & 11.4 & 21.9 & 44.0 & 53.0 & 10.5 & 29.0 & & ail \\
\hline
\end{tabular}

where F1 is the First floor and GF is the Ground floor of the clubhouse.

\section{Discussion}

Defects that affect the energy performance of the Clifton clubhouse are evaluated using the proposed energy investigation framework. Brick and block walls, which are assumed to be homogeneous layers, are revealed to have a range of thermal bridges between connecting mortar joints. During the model calibration, the mortar joints initially are assumed to have a thermal conductivity of $0.93 \mathrm{~W}^{-1} \mathrm{~K}^{-1}$, which is the thermal conductivity of a dry mortar. However, the infrared thermography phase revealed that the thermal conductivity of mortar joints is $1.5 \mathrm{~W}^{-1} \mathrm{~K}^{-1}$, which is, in reality, the thermal conductivity of a moist mortar. These changes are input to the building simulation model. After this update, FE model and thermography analysis results correspond. An analysis of temperature profiles also reveals that mortar joints behave as thermal bridges with a heat flux of $15 \mathrm{~W} / \mathrm{m}^{2}$ (see Figure 13)

The purpose of expansion joints is to accommodate thermal loads, which force buildings to expand and contract, thus making expansion joints weak insulators and sources of thermal bridges (see Figure 8 (top)) . The analysis of expansion joints, selected in the case study, reveals that the high heat loss is at steel frame cramps in the walls. Steel cramps have high thermal conductivity and are placed to provide a bound between bricks and blocks. The linear thermal bridge created by steel cramps could be due to the discontinuity of insulation, which decreases the thermal resistance of the envelope and increases the heat flow. The heat losses within the expansion and mortar joints are $27.54 \mathrm{~W} / \mathrm{m}^{2}$ and $15.9 \mathrm{~W} / \mathrm{m}^{2}$, (see Figure 13). This phenomenon, however, could only be found when investigating plans of the external wall (see Figure 7).

Cracks within the building envelope, which may have formed due to the building settlement, are observed to affect the surface temperatures of internal walls. Figure 5 shows that temperature at 
cracks is about $1.5^{\circ} \mathrm{C}$ lower than temperature for the rest of the wall. Cracks behave as heat sinks within the building envelope. However, due to insulated layer within the wall, cracks on external walls have no influence on the inner surface temperature.

Domestic hot water pipes have a great influence on indoor temperature. Due to a combination of convection from the vents of the heat recovery and radiation from hot water pipes the indoor temperature rises. Figure 16 shows temperature time histories of a model with and without hot water pipes. The model with the hot water pipes has approximately $3^{\circ} \mathrm{C}$ higher operational temperature than the model without hot water pipes. As a result of the mechanical ventilation being switched off during Christmas (a no-occupancy period), the temperature difference is observed to have more influence on the model without pipes.

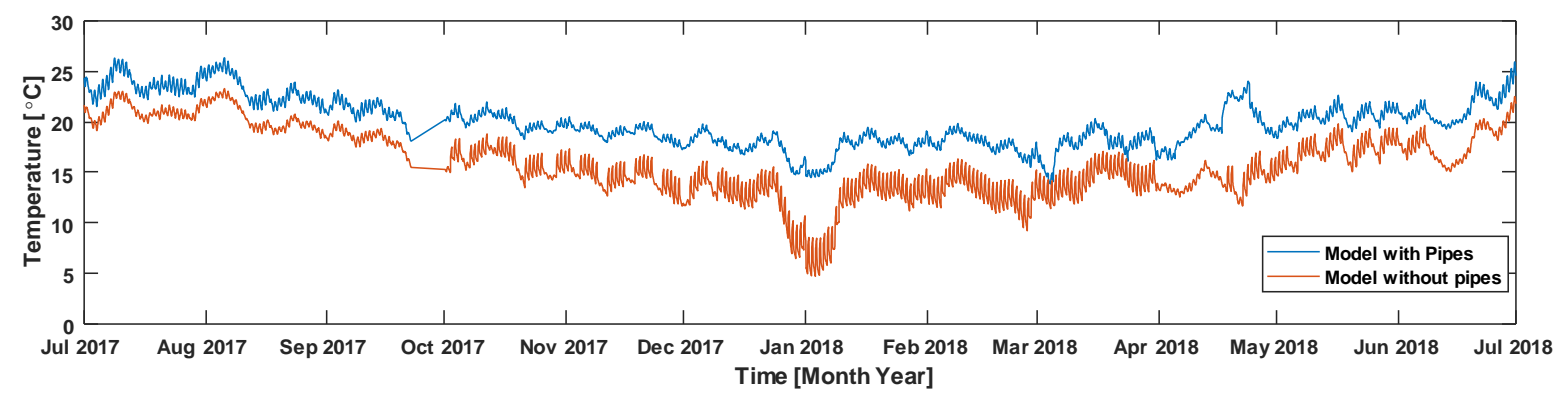

Figure 16: Influence of hot water pipe on temperature in the changing room.

\section{Conclusion}

This study proposes a building energy investigation framework, which combines infrared thermography and computer simulation phases to analyse effects of thermal bridges on the performance of a building and predict building performance using future weather data. The infrared thermography phase is composed of the analysis of thermal images of the building and generation of numerical models simulating thermal conductivity of building parts with thermal bridges. The computer simulation phase encompasses the design of building energy simulation model and measurement collection of the structure of interest. Measured temperatures are used to validate the simulation model. Effects of thermal bridges and building performance with anticipated climate changes are simulated inputting $\mathrm{U}$ - and psi-values, which are calculated at the infrared thermography analysis phase. A clubhouse, which is designed as a low energy building, serves as a case study to demonstrate the application of the proposed energy investigation framework.

The study draws the following conclusions:

1) The proposed building energy investigation framework provides a guidance on the building performance analysis and evaluation. The validation and calibration of (i) models of building parts with thermal bridges and (ii) building energy simulation models are useful when evaluating building performance, accounting for possible energy savings (by minimising effects of thermal bridges), and predicting future performance of the building. Using the proposed framework, areas that influence the energy consumption of a building such as cracks, thermal bridges and hot water pipes can be characterized.

2) The risk of overheating in buildings around Europe has been undermined in recent years. With recent weather events and trends in global warming, buildings need to adapt uncertainties of the weather. Assessing the risk of overheating in buildings should be mandatory, especially considering that temperature will rise in the future. The case study revealed that, under the 
two-current method of overheating assessment (CIBSE Guide A and TM52), the clubhouse is in a high risk of overheating.

3) Mortar and expansion joints and cracks create weak areas within the building envelope. These areas affect the air exchange within the building and increase infiltration, thus the energy efficiency of the building reduces. In the case study, heat losses through thermal bridges in expansion joints with steel frame cramps and cracks increased the gas consumption by $18 \%$ and $5 \%$ during winter and summer, respectively. The heat flow through the clubhouse walls increased by about $11 \%$ and $2 \%$ in winter and summer, respectively. Furthermore, eliminating thermal bridges resulting from cracks and joints could save up to $18 \%$ on the gas consumption bill.

\section{ACKNOWLEDGEMENT}

This study was funded by Petroleum Technology Development Fund (PTDF), Nigeria and REMOURBAN project that is supported by the EU Horizon 2020 research and innovation programme under grant agreement No 646511

\section{References}

[1] United Nation, Global Status Report 2017. 2017.

[2] BBC, "Heatwave: 2018 was the joint hottest summer for UK - BBC News." [Online]. Available: https://www.bbc.co.uk/news/uk-45399134. [Accessed: 23-Oct-2018].

[3] M. McGrath, "Climate change: 'Hothouse Earth' risks even if $\mathrm{CO} 2$ emissions slashed - BBC News." [Online]. Available: https://www.bbc.co.uk/news/science-environment-45084144. [Accessed: 23-Oct-2018].

[4] A. P. Ramallo-González, M. E. Eames, and D. A. Coley, "Lumped parameter models for building thermal modelling: An analytic approach to simplifying complex multi-layered constructions," Energy Build., vol. 60, pp. 174-184, 2013.

[5] J. A. Clarke, Energy Simulation in Building Design, 2nd ed. 2001.

[6] F. Ascione, N. Bianco, F. De Rossi, G. Turni, and G. P. Vanoli, "Different methods for the modelling of thermal bridges into energy simulation programs: Comparisons of accuracy for flat heterogeneous roofs in Italian climates," Appl. Energy, vol. 97, pp. 405-418, 2012.

[7] "BS EN ISO 10211 : 2017 BSI Standards Publication Thermal bridges in building construction Heat flows and surface temperatures - Detailed calculations," 2017.

[8] F. Sierra, J. Bai, and T. Maksoud, "Impact of the simplification of the methodology used to assess the thermal bridge of the head of an opening," Energy Build., vol. 87, pp. 342-347, 2015.

[9] F. Baba and H. Ge, "Dynamic effect of balcony thermal bridges on the energy performance of a high-rise residential building in Canada," Energy Build., vol. 116, pp. 78-88, 2016.

[10] S. A. Al-Sanea and M. F. Zedan, "Effect of thermal bridges on transmission loads and thermal resistance of building walls under dynamic conditions," Appl. Energy, vol. 98, pp. 584-593, 2012.

[11] F. Ascione, N. Bianco, R. F. De Masi, F. De'Rossi, and G. P. Vanoli, "Simplified state space representation for evaluating thermal bridges in building: Modelling, application and validation of a methodology," Appl. Therm. Eng., vol. 61, no. 2, pp. 344-354, 2013.

[12] F. Bianchi, A. L. Pisello, G. Baldinelli, and F. Asdrubali, "Infrared thermography assessment of 
thermal bridges in building envelope: Experimental validation in a test room setup," Sustain., vol. 6, no. 10, pp. 7107-7120, 2014.

[13] H. Ge and F. Baba, "Dynamic effect of thermal bridges on the energy performance of a low-rise residential building," Energy Build., vol. 105, pp. 106-118, 2015.

[14] K. Kuusk, J. Kurnitski, and T. Kalamees, "Calculation and compliance procedures of thermal bridges in energy calculations in various European countries," Energy Procedia, vol. 132, pp. 27-32, 2017.

[15] K. Martin, A. Erkoreka, I. Flores, M. Odriozola, and J. M. Sala, "Problems in the calculation of thermal bridges in dynamic conditions," Energy Build., vol. 43, no. 2-3, pp. 529-535, 2011.

[16] P. De Wilde, "The gap between predicted and measured energy performance of buildings: A framework for investigation," Autom. Constr., vol. 41, pp. 40-49, 2014.

[17] F. Asdrubali, G. Baldinelli, and F. Bianchi, "A quantitative methodology to evaluate thermal bridges in buildings," Appl. Energy, vol. 97, pp. 365-373, 2012.

[18] M. Fox, D. Coley, S. Goodhew, and P. De Wilde, "Thermography methodologies for detecting energy related building defects," Renew. Sustain. Energy Rev., vol. 40, pp. 296-310, 2014.

[19] A. Kylili, P. A. Fokaides, P. Christou, and S. A. Kalogirou, "Infrared thermography (IRT) applications for building diagnostics: A review," Appl. Energy, vol. 134, pp. 531-549, 2014.

[20] H. Wang and Z. (John) Zhai, "Advances in building simulation and computational techniques: A review between 1987 and 2014," Energy Build., vol. 128, pp. 319-335, 2016.

[21] T. Hong, S. . Chou, and T. . Bong, "Building simulation: an overview of developments and information sources," Build. Environ., vol. 35, no. 4, pp. 347-361, 2000.

[22] V. Martinaitis, E. K. Zavadskas, V. Motuzienè, and T. Vilutienè, "Importance of occupancy information when simulating energy demand of energy efficient house: A case study," Energy Build., vol. 101, pp. 64-75, 2015.

[23] E. Rodriguez Jara, F. J. Sanchez de la Flor, S. Allvarez Dominguez, J. L. Molina Felix, and J. M. Salmeron Lissen, "A new analytical approach for simplified thermal modelling of buildings: SelfAdjusting RC-network model," Energy Build., vol. 130, pp. 85-97, 2016.

[24] "Prometheus Project," University of Exeter. [Online]. Available: https://emps.exeter.ac.uk/engineering/research/cee/research/prometheus/. [Accessed: 15May-2018].

[25] S. S. M. Danish, T. Senjyu, M. A. Ibrahimi, M. Ahmadi, and M. A. Howlader, "A managed framework for energy-efficient building," J. Build. Eng., vol. 21, pp. 120-128, 2019.

[26] A. U. Weerasuriya, X. Zhang, V. J. L. Gan, and Y. Tan, "A holistic framework to utilize natural ventilation to optimize energy performance of residential high-rise buildings," Building and Environment, vol. 153. pp. 218-232, 2019.

[27] V. Lapinskiene and V. Martinaitis, "The framework of an optimization model for building envelope," Procedia Eng., vol. 57, pp. 670-677, 2013.

[28] D. Fosas, D. A. Coley, S. Natarajan, M. Herrera, M. Fosas de Pando, and A. Ramallo-Gonzalez, "Mitigation versus adaptation: Does insulating dwellings increase overheating risk?," Build. Environ., vol. 143, no. May, pp. 740-759, 2018.

[29] K. Konis, A. Gamas, and K. Kensek, "Passive performance and building form: An optimization 
framework for early-stage design support," Sol. Energy, vol. 125, pp. 161-179, 2016.

[30] M. K. Najjar, K. Figueiredo, A. W. A. Hammad, V. W. Y. Tam, A. C. J. Evangelista, and A. Haddad, "A framework to estimate heat energy loss in building operation," Journal of Cleaner Production, vol. 235. pp. 789-800, 2019.

[31] T. G. Theodosiou and A. M. Papadopoulos, "The impact of thermal bridges on the energy demand of buildings with double brick wall constructions," Energy Build., vol. 40, no. 11, pp. 2083-2089, 2008.

[32] J. Ramalho de Freitas and E. Grala da Cunha, "Thermal bridges modeling in South Brazil climate: Three different approaches," Energy Build., 2018.

[33] B. Lehmann, K. Ghazi Wakili, T. Frank, B. Vera Collado, and C. Tanner, "Effects of individual climatic parameters on the infrared thermography of buildings," Appl. Energy, vol. 110, pp. 2943, 2013.

[34] C. Serra, A. Tadeu, and N. Simões, "Heat transfer modeling using analytical solutions for infrared thermography applications in multilayered buildings systems," Int. J. Heat Mass Transf., vol. 115, pp. 471-478, 2017.

[35] R. Albatici, A. M. Tonelli, and M. Chiogna, "A comprehensice experimental approach for the validation of quantitative infrared thermography in the evaluation of building thermal transmittance," Energy Build., vol. 141, 2015.

[36] S. Sfarra, A. Cicone, B. Yousefi, C. Ibarra-castanedo, S. Perilli, and X. Maldague, "Improving the Detection of Thermal Bridges in Buildings Via on Site Infrared Thermography:the Potentialities of Innovative Mathematical Tools," vol. 182, pp. 159-171, 2018.

[37] M. O'Grady, A. A. Lechowska, and A. M. Harte, "Quantification of heat losses through building envelope thermal bridges influenced by wind velocity using the outdoor infrared thermography technique," Appl. Energy, vol. 208, no. September, pp. 1038-1052, 2017.

[38] R. Kromanis and P. Kripakaran, "Advanced Engineering Informatics Data-driven approaches for measurement interpretation: analysing integrated thermal and vehicular response in bridge structural health monitoring," Adv. Eng. Informatics, vol. 34, pp. 46-59, 2017.

[39] BS EN ISO 9869, "BSI Standards Publication Thermal insulation - Building elements - In- situ measurement of thermal resistance and thermal transmittance Part 1: Heat flow meter method," BSI Stand., 2018.

[40] BS EN ISO 13187, "Thermal performance of buildings - Qualitative detection of thermal irregularities in building envelopes - Infrared method," Br. Stand. Inst., p. 16, 1999.

[41] R. Andarini, "The role of building thermal simulation for energy efficient building design," Energy Procedia, vol. 47, pp. 217-226, 2014.

[42] E. Lo, Z. Ma, D. Borelli, and C. Schenone, "Residential building retrofit through numerical simulation : a case study," Energy Procedia, vol. 111, no. September 2016, pp. 91-100, 2017.

[43] M. Rahman, M. Rasul, and M. M. K. Khan, "Energy conservation measures in an institutional building by dynamic simulation using DesignBuilder," Proc. 3rd IASME/WSEAS Int. Conf. Energy Environ. (EE '08), Pap., no. 565-266, pp. 192-197, 2008.

[44] S. Yu, Y. Cui, X. Xu, and G. Feng, "Impact of Civil Envelope on Energy Consumption based on EnergyPlus," Procedia Eng., vol. 121, pp. 1528-1534, 2015.

[45] C. P. Underwood, "An improved lumped parameter method for building thermal modelling," 
Energy Build., vol. 79, pp. 191-201, 2014.

[46] M. M. Rahman, M. G. Rasul, and M. M. K. Khan, "Energy conservation measures in an institutional building in sub-tropical climate in Australia," Appl. Energy, vol. 87, no. 10, pp. 2994-3004, 2010.

[47] M. Doran, S and T. Gorgolewski, M, "BRE DIGEST 465: U-Values for light steel-frame construction," vol. 37, pp. 257-268, 2012.

[48] BSI, "BS EN ISO 6946:2007 - Building components and building elements. Thermal resistance and thermal transmittance. Calculation method," Br. Stand. Inst., 2007.

[49] CIBSE, Environment Design. 2006.

[50] ANSYS, “ANSYS Theory Reference." p. 1286, 2000.

[51] UK Met Office, "Weather and climate change - Met Office." [Online]. Available: https://www.metoffice.gov.uk/. [Accessed: 31-Jul-2019].

[52] American Society of Heating Refrigeration and Air Conditioning, ASHRAE Guideline 14: Measurement of Energy and Demand Savings. 2002.

[53] Y. Li and Y. Rezgui, "A novel concept to measure envelope thermal transmittance and air infiltration using a combined simulation and experimental approach," Energy Build., vol. 140, pp. 380-387, 2017.

[54] T. Hong, S. C. Taylor-lange, S. D. Oca, D. Yan, and S. P. Corgnati, "Advances in research and applications of energy-related occupant behavior in buildings $\Xi_{\text {,., }}$ Energy Build., vol. 116, pp. 694-702, 2016. 